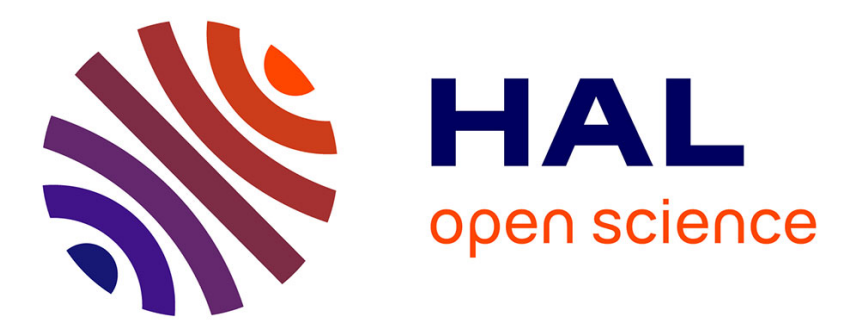

\title{
Design and implementation of a heliostat for atmospheric spectroscopy
}

Marie-Hélène Mammez, Raphaël Vallon, Frédéric Polak, Bertrand Parvitte, Virginie Zéninari

\section{- To cite this version:}

Marie-Hélène Mammez, Raphaël Vallon, Frédéric Polak, Bertrand Parvitte, Virginie Zéninari. Design and implementation of a heliostat for atmospheric spectroscopy. Infrared Physics and Technology, 2019, 97, pp.235-243. 10.1016/j.infrared.2019.01.006 . hal-01994631

\section{HAL Id: hal-01994631 \\ https://hal.univ-reims.fr/hal-01994631}

Submitted on 21 Oct 2021

HAL is a multi-disciplinary open access archive for the deposit and dissemination of scientific research documents, whether they are published or not. The documents may come from teaching and research institutions in France or abroad, or from public or private research centers.
L'archive ouverte pluridisciplinaire HAL, est destinée au dépôt et à la diffusion de documents scientifiques de niveau recherche, publiés ou non, émanant des établissements d'enseignement et de recherche français ou étrangers, des laboratoires publics ou privés.

\section{(ㄷ)(1) $\$$}

Distributed under a Creative Commons Attribution - NonCommerciall 4.0 International 


\title{
Design and implementation of a heliostat for atmospheric spectroscopy
}

\author{
Marie-Hélène Mammez, Raphaël Vallon, Frédéric Polak, Bertrand Parvitte, \\ Virginie Zéninari \\ Groupe de Spectrométrie Moléculaire et Atmosphérique (GSMA), UMR CNRS 7331, \\ Université de Reims Champagne-Ardenne, B.P.1039, 51687 Reims Cedex 2, France
}

\begin{abstract}
The spectrometry is an important tool for atmospheric studies. In particular, passive spectrometric analysis implies associating a spectrometer with a heliostat. Indeed the heliostat enables to compensate for the Earth rotation relative to the Sun. In this way the sunlight can be collected at any time in order to detect atmospheric gases. Unfortunately, the instruments described in the literature need to be placed close to the spectrometer $(<5 \mathrm{~m})$ that is insufficient for the layout of our laboratory. So a servo-controlled heliostat, which is able to track the Sun with a great stability for several hours and which can be placed at a big distance from the spectrometer $(>10 \mathrm{~m})$, has been designed and built. Keywords: Heliostat; coordinate system; servo control; FTIR; atmospheric spectroscopy
\end{abstract}

\section{Introduction: context and state-of-art}

Optical laser spectrometry is a tool based on the Beer-Lambert law and widely used for atmospheric studies, either in situ — for example CEAS (Cavity Enhanced Absorption Spectroscopy) [1] and photoacoustic spectroscopy [2] — or remotely — for example LIDAR (Light Detection And Ranging) [3] and heterodyne spectrometry [4]. The heterodyne spectroscopy is a passive groundbased technique particularly used for atmospherical $[5,6]$ and astrophysical

Email address: virginie.zeninari@univ-reims.fr (Virginie Zéninari) 
studies [7]. In the atmospherical case, a part of the sunlight must be collected by a heliostat and superimposed to a local oscillator beam in order to create a beat note signal.

There are mainly two types of heliostat structures which enable to collect the solar beam for its spectrometric analysis: the systems with equatorial mounts [8] and the systems with altazimuthal mounts [9]. Equatorial mounts enable a precise Sun tracking but have the disadvantage of transmitting a mobile output beam which is unsuitable with the heterodyne measurement (no possible superposition with the local oscillator beam). On the contrary, the altazimuthal mounts lead to a fixed output beam. A commercial version (Bruker A547) of this kind of instrument is available and has been successfully used [10, 11]. Nonetheless the optical path length between tracker head and quadrant detector must not exceed $5 \mathrm{~m}$ [12].

If the spectrometer is located far from the roof, a non-commercial altazimuthal structure is preferable. Among those systems, the Sun tracking can be carried out either by calculation or by a servo loop. Contrary to trackers with a servo loop, the computed tracking can't take into account the atmospheric perturbations which cause unpredictable beam movements [13].

The servo control is often carried out by generating an error signal from a quadrant photodiode [14] or a camera [15]. A quadrant photodiode delivers an error signal which depends on the power distribution and the shape of the solar beam. A camera is the best system to generate the error signal because it enables to consider the form of the tracked object, for example in the case of the Moon. But it requires to use a heavy image processing to calculate the Sun position and generate an error signal. In those two cases, the raw error signal isn't efficient to correct the rotation of the instrument: first it must be compared with the approximate calculation of the solar position via a matrix processing $[16,17,18,19]$. As a result, the servo-controlled tracking becomes delicate close to the zenith because the azimuth angle isn't discriminative there and can take any value. Therefore with this servo-control method the heliostat becomes uncontrollable close to the zenith. Existing instruments usually bypass this 
problem by temporarily disengaging the servo loop for the azimuthal rotation [14]. Thus monitoring is less effective in the middle of the day. To avoid the complete stop of the azimuthal servo-control, its parameters PID (proportional - integral - derivative) could be adapted according to the time. Recently, Volkov et al. [20] defined an optimization method which enables to solve the stability loss near the zenith.

The GSMA is currently developing a heterodyne spectrometer using quantum cascade lasers as local oscillator. In vue to use our heterodyne spectrometer for atmospheric studies, we have developed a heliostat. We report here the development of a servo-controlled instrument adapted to the constraints imposed by infrared heterodyne spectrometry and the layout of the places (need to obtain a fixed output beam, $10 \mathrm{~m}$ distance between the heliostat and the spectrometer). It's a servo-controlled instrument for which the error signal is produced by a lateral effect photodiode (LEP) and is independent of the shape, size or power distribution of the incident beam. The servo-control method that we present is a bit different than Volkov et al.'s [20] but enables to track efficiently the Sun whatever the time, without the complexity of an adaptive PID and without the stability loss near the zenith.

\section{Experimental set-up and operating principle}

\subsection{Optical set-up}

The heliostat or suntracker that we built is composed of two plane mirrors $M_{1}$ and $M_{2}$ with elliptical section (see Figure 1). They are inclined at $45^{\circ}$ relative to the vertical of the location. $M_{2}$ adjusts the zenithal angle $\theta_{2}$ and the set $\left\{M_{1}+M_{2}\right\}$ ensures the $\theta_{1}$ azimuthal rotation. The mirrors are connected to motorized rotation stages. It is split into two paths by a $\mathrm{BaF}_{2}$ beamsplitter (reflection of $4 \%$ per side). The reflected beam is focused on a Lateral Effect Photodiode (LEP, PDP90A - Thorlabs), sensitive to visible radiation, and which enables the servo-control suntracking. The transmitted beam is redirected by two plane mirrors towards the spectrometer through a skylight. This device enables to collect a total power beam of $\sim 390 \mathrm{~mW}$ by full sunlight. 


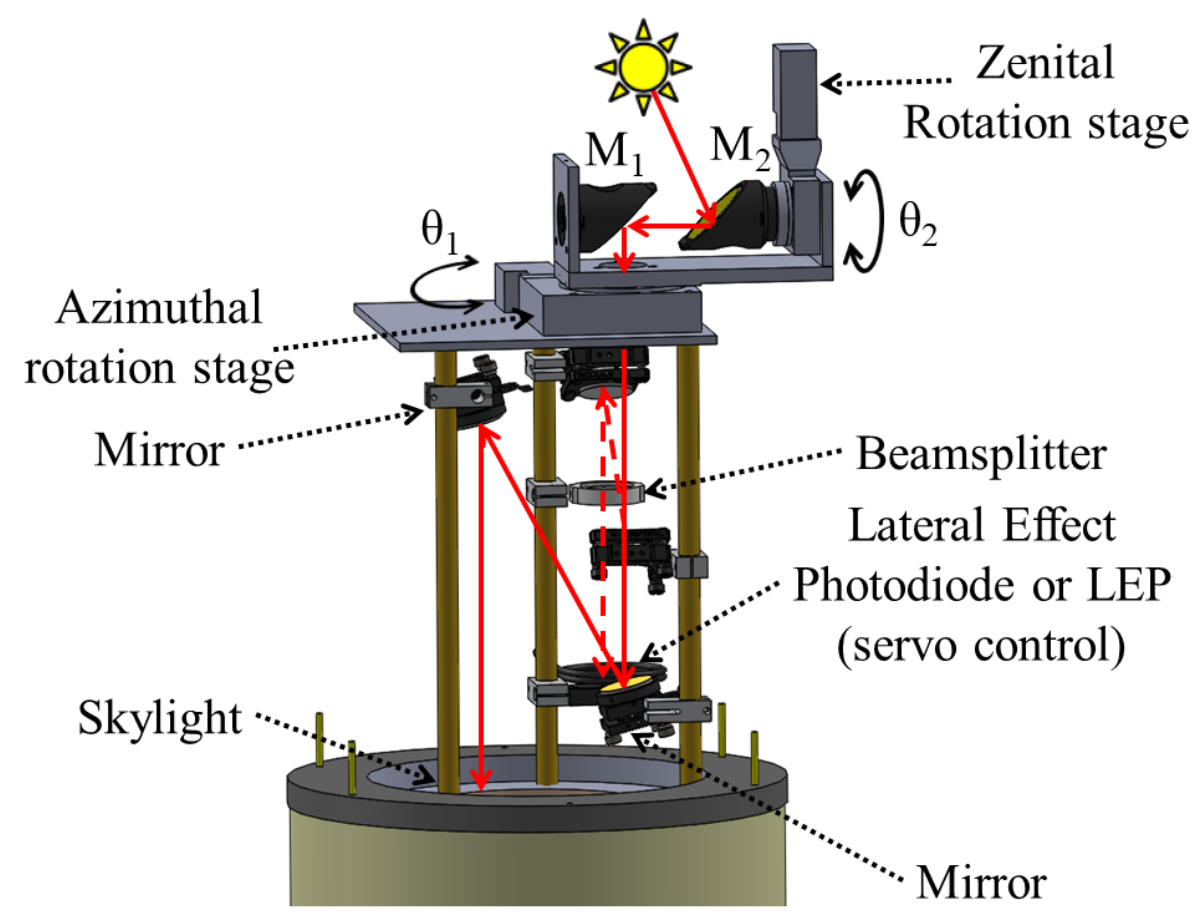

Figure 1: Optical set-up. A fraction of the sunlignt is taken by $\mathrm{M}_{2}$ mirror and transmited by the $\mathrm{M}_{1}$ mirror through a hole in the azimuthal stage $(4.5 \mathrm{~cm}$-aperture). The transmitted beam is divided in two parts: the first is directed towards the spectrometer via the skylight; the second is focused on a lateral effect photodiode for the servo control. The whole setup is placed on the roof of the laboratory. 
The heliostat is protected by a double-walled housing to limit parasitic illumination of the LEP and disturbances due to wind. It is surmounted by an electro-pneumatic opening lid. Ventilation and heating system have been added to minimize moisture inside the box and avoid deterioration of optics.

For safety reasons, the closing of the system has been designed so as to minimize the need to access the roof. The tilting lid is caused by a pneumatic piston whose control is provided from the experiment room. The lid control program communicates with the rotation stages and with a reading program of a weather probe (WTX510 - Vaisala). It enables to protect the device in inclement weather by an automatic stop and closure of the tracker.

\subsection{Field of view and angular resolution}

Accurate solar tracking is a critical component of many quantitative approaches to remote sounding of our atmosphere. The retrieval of trace gas columns from an observed solar spectrum requires precise knowledge of the instruments line-of-sight (LOS) at the time of observation. The required stability for this kind of applications is typically better than $\pm 0.01^{\circ}$ ( $\left.\pm 36 \operatorname{arcsec}\right)$ [21]. For measurements with FTIR specrometers [22] and for heterodyne measurements it is also necessary to maintain a constant light intensity. So it must be ensured that the target point is always the same, for example the center of the Sun. Thus the whole image must be perceived on the LEP for a good pointing. This is only possible if the apparent diameter of the Sun $(\alpha=9 \mathrm{mrad})$ is smaller than the field of view (FOV) of the device, as it is shown on Figure 2. Otherwise a shift smaller than the apparent diameter of the Sun will not be perceived by the servo system (Figure 2). In practice, the FOV is limited by the smallest field of view of the components of the heliostat [14].

$$
F O V=\min \left(F O V_{1}, F O V_{2}\right)>9 \operatorname{mrad}
$$


where

$$
\begin{aligned}
& F O V_{1}=\arctan \frac{\phi_{D}}{f} \\
& F O V_{2}=\arctan \frac{\phi_{T}}{L_{0}}
\end{aligned}
$$

and with:

- $F O V_{1}$ : the field of view of the LEP

- $F O V_{2}$ : the field of view of the beamsplitter

- $\phi_{D}=10 \mathrm{~mm}$ : the diameter of the LEP,

- $f=12.5 \mathrm{~cm}$ : the focal length of the lens which focus the beam on the LEP,

- $\phi_{T}$ : the aperture diameter of the heliostat (i.e. the aperture diameter of the azimuthal rotation stage),

- $L_{0}$ : the distance between the suntracker and the servo system.

The stage selected for the zenithal rotation has a resolution of $2.1 \mu \mathrm{rad}$ for a $2 \mathrm{~cm}$-aperture (M-060.DG - PI - Physik Instrumente). The stage of the azimuthal rotation has a resolution of $0.96 \mu \mathrm{rad}$ for a $4.5 \mathrm{~cm}$-aperture (M-062.DG - PI). As we can see on Figure 2, the field of view of the instrument is limitted by the aperture of the azimuthal stage. That means the distance $L_{0}$ must be smaller than $5 \mathrm{~m}$. However, the spectrometer is placed in the experimental room at $L \approx 10 \mathrm{~m}$ from the roof. So the servo system must be set up on the roof near the stages for a sufficient field of view ( $c f$ equation 1 ).

Although the heliostat is designed to operate with a servo loop, the use of a LEP for generating the error signal requires to roughly know the position of the Sun in order to illuminate the LEP and get a starting error signal. Consequently the heliostat must first be programmed to calculate and reach an adequate starting position. Then, the servo loop enables to center the beam on the LEP. The zenithal and azimuthal angles are considered correct when the image of the Sun coincides with the LEP center. 


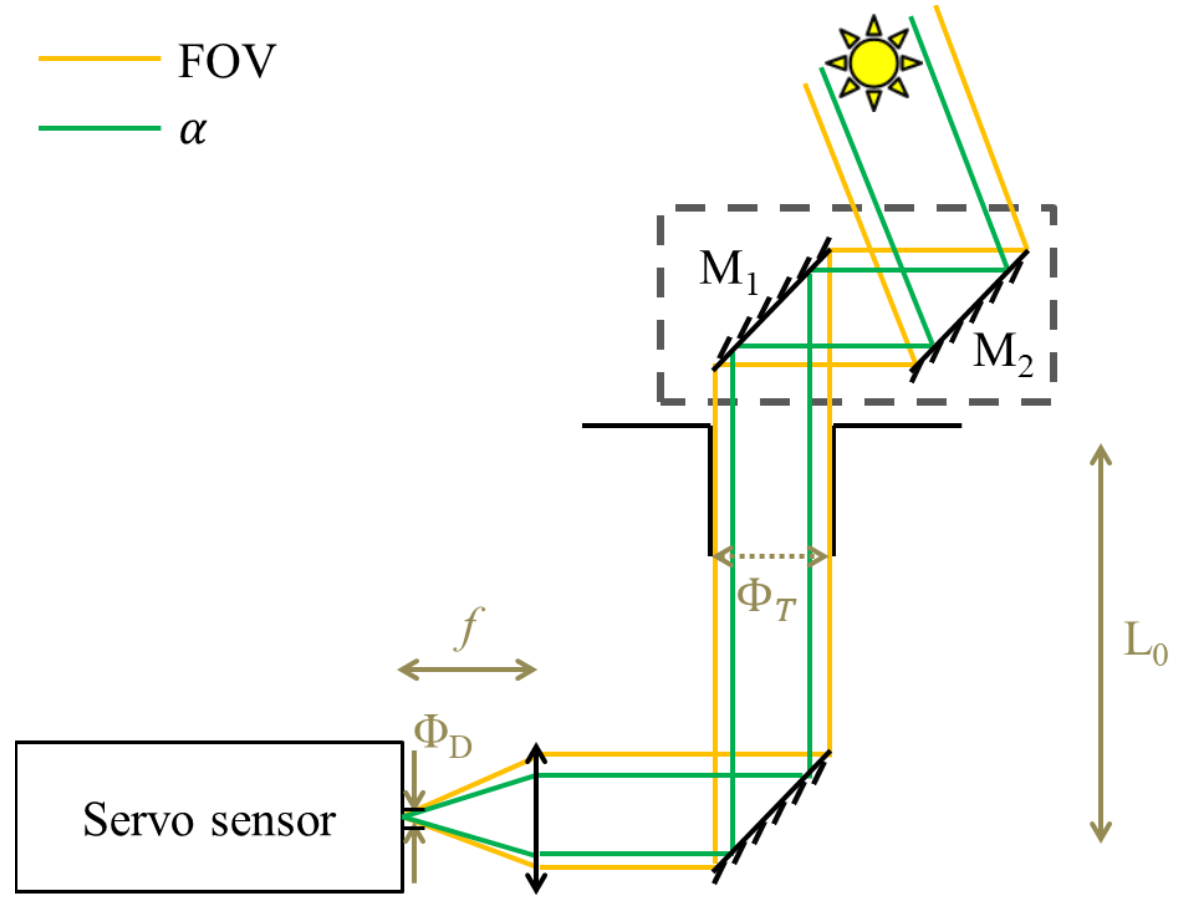

Figure 2: Impact of the field of view of the heliostat on the servo loop: if $F O V>\alpha$ the control accuracy is limited by the sensor resolution. In our case, it requires placing the servo device on the roof because of the too small aperture of the azimuthal stage. 


\section{Calculation of solar positions}

In the case of a perfectly oriented instrument, the suntracking can be done by calculating its positions during the day. A Matlab program using the algorithm of Jean Meeus is used [23, 24]. Zenithal and azimuthal angles of the Sun are obtained in a topocentric coordinate system. The calculation is made from the geographical coordinates of the tracker, the date, time and offset relative to Coordinated Universal Time (UTC). The zenithal angle $\theta_{2}$ is measured relative to the local vertical, that is to say the altitude alt $=90^{\circ}-\theta_{2}$. The azimuthal angle $\theta_{1}$ is measured in the tangent plane to the Earth from North and eastward (Figure 3). This reference is named topocentric coodinate system and is sketched on Figure 3.

The algorithm calculates the position of the Sun between -2000 and 6000 years, with an uncertainty of $0.0003^{\circ}$ or $5.2 \mu \mathrm{rad}$. This precision is degraded for large zenithal angles because of atmospheric refraction. It is also limited by the irregular variations of the Earth rotation. In addition, due to the imperfect orientation of the heliostat, the coordinate system considered in the calculation doesn't coincide with the real coordinate system of the physical instrument. This difference corresponds to an angular shift between the two coordinate systems and leads to an increasing of the measured error. A total error of $\pm 2.2^{\circ}$ is measured on the zenithal angle; and a total error of $\pm 8.1^{\circ}$ is measured on the azimuthal angle. These results are reported on Figure 4 (a). Under these conditions the LEP of the servo control is not illuminated.

Generally, Euler angles are used to correct the orientation error of the instrument [20] as they represent the angular shift between the theoretical coordinate system and the real one. A correction with this method enables to reduce the error of $27 \%$ for zenithal angles, and $88 \%$ for azimuths. But in our case it was not enougth to get a beam down our skylight. That's why we preferred to realise a calibration of our setup, which is made by fitting the curve of the calculated positions compared to the measured positions. The maximum error is then reduced to $\pm 0.9^{\circ}$ for zenithal angles and $\pm 0.2^{\circ}$ for azimuths, as it is shown 
on Figure 4 (b). So, the calculation accuracy is improved by $59 \%$ for zenithal angles and by $99 \%$ for azimuths. We can note that the calibration method is here twice better than Euler angles method to correct zenithal error. Moreover the beam reaches the bottom of the skylight.

After the correction on the calculated Sun position, the beam shift measured down the skylight is $16 \mathrm{~cm}$ depending on the zenithal rotation and $3.5 \mathrm{~cm}$ depending on the azimuthal rotation. This shift is not a problem here because the calculation is only used to illuminate the LEP placed on the roof (up the skylight): the beam is centered on the LEP in a second step by the servo loop. More details about the calculation correction are reported in [25].

\section{Servo loop}

The servo system consists in generating an error signal for correcting the rotation of the mirrors through a feedback loop. This is usually associated with a PID to optimize the response time. Generating the error signal can typically be made by a quadrant photodiode $[14,26,27]$ or a camera [15]. A LEP (PDP90A - Thorlabs) which has an intermediate comportment was chosen. It enables to determine the position of the Sun's image on its surface, regardless of its form or power distribution, and avoiding the constraints related to image processing.

The calculation presentef in section 3 enables to illuminate the LEP which then generates two error signals (voltages) indicating the differences in $\mathrm{X}$ and $\mathrm{Y}$ between the beam position and the center of the LEP. Those signals are coupled signals which depend on movements of the two stages. The $\mathrm{X}$ and $\mathrm{Y}$ error signals produced by the LEP are correlated and both of them depend on angles imposed on the two rotation stages. Therefore the error signals can not be used independently of each other. Both of them contribute to the correction of the positions of the two stages. This phenomenon is highlighted in Figure 5 where the servo control is turned off and each stage is manually moved to see the movement induced on the beam.

Selected stages operate in a closed loop, that is to say, our program indicates the target-angle to the controller (C-863 - PI) which transmits the movement 
command to the stage and checks whether the displacement occurs (unlike the open loop stages that only transmit order without testing execution). Moreover, the stages do not have analog input and are chained on a single controller (series circuit). Consequently the error signal from the LEP can not be directly transmitted to a stage. It must be processed to determine the angular correction to be imposed. This correction is then digitally transmitted by the controller to the stage. Therefore, the traditional setting of a PID can not be implemented.

The servo loop is mainly limited by the error signals coupling. One solution is to calculate an approximate sunposition to know the sign of the correction to apply and then rotating step by step the azimuthal and zenithal stages to optimize the error signal [14]. Using such a method with altazimuthal geometry leads to an anarchic response of the system approaching the zenith $\left(\theta_{2}=0\right)$. At this time of the day, the error signal is not strictly discriminative since the Sun can be found whatever the value of the azimuthal angle. This problem is often bypassed by disengaging the servo loop of the azimuthal rotation when the Sun is near the zenith. Another solution consists in using an adaptive PID. None of these operations is required with the servo method developed in this work and detailed below.

As it is shown on Figure 5, the rotational movement of each stage results in a curvilinear motion on the LEP assimilable with a straight line around its center. Each of the two straight lines represents the coordinate axis of the associated stage. So the altazenithal coordinate system can be projected in the coordinate system of the LEP, as it is shown on Figure 6. As the rotation stages axis are perpendicular to each other, the zenithal axis is always perpendicular to the azimuthal one; and the modeling of the altazimuthal coordinate system can be simplified by focusing on the movement of azimuthal axis. During the day, the projection of the altazimuthal coordinate system (coordinate sytem of the rotation stages) turns with an angle $\varphi$ relative to the coordinate system of the LEP, as displayed in Figure 6. This movement is independent of the path of the Sun but only depends on the mecanical position imposed to the azimuthal stage. Indeed, the rotation stages of the heliostat and the LEP of the servo are 
fixed on a common mechanical structure, so the correspondence between the two systems can't be modified.

The angle $\varphi$ was recorded during one day. Its expression is established depending on the azimuth by fitting the curve on Figure 7 (a). The fit is calculated in such a way as to impose a strictly increasing evolution to $\varphi$ and so to prevent degeneracy of the azimuth near the zenith $\left(\theta_{2}=0\right)$. At this time of the day, just one azimuthal value is now allowed, and there is no anarchic response of the tracker. During the tracking, $\varphi$ is estimated from the azimuthal angle measurement. Then the $\mathrm{X}$ and $\mathrm{Y}$ values measured on the LEP are projected onto zenithal and azimuthal axes noted $\mathrm{x}$ and $\mathrm{y}$ using equation 4. This process is described on Figure 7 (b). Therefore, two new error signals independent from each other are generated (one for each stage). Azimuthal and zenithal angles can be then adjusted in decoupled and simultaneous steps.

$$
\left\{\begin{array}{l}
x=-X \cos \varphi+Y \sin \varphi \\
y=X \sin \varphi+Y \cos \varphi
\end{array}\right.
$$

The servo loop effect on the suntracking is shown on Figure 8 (a) and Figure 9 (a). The observed behavior is consistent with that of a conventional servo loop using PID. On the roof, the amplitude of displacement of the solar spot on the surface of the LEP after focusing $\left(\mathrm{BaF}_{2}\right.$ lens with a $12.5 \mathrm{~cm}$ focal length) is $12 \mu \mathrm{m}$ along the $\mathrm{X}$ axis and $7.4 \mu \mathrm{m}$ along the $\mathrm{Y}$ axis (Figure 8 (b) and Figure 9 (b)).

Although this servo loop is not programmed with a conventional PID, it still enables to replicate its behavior. The angular correction is proportional to the error signal which is similar to a P setting. The I integration aspect is connected to the repetition rate of the servo loop: the loop time is imposed at a maximum duration of $850 \mathrm{~ms}$. Only the derivation D setting is not taken into account: it is not essential because the Sun movement is slow $(73 \mu \mathrm{rad} / \mathrm{s})$.

Down the skylight, a part of the beam is focused on a second LEP using a second $\mathrm{BaF}_{2}$ lens with a $50 \mathrm{~mm}$ focal length to quantify the beam stability at 
$L=10 \mathrm{~m}$ from the heliostat. As it is displayed on Figure 8 (c) and Figure 9 (c), the amplitude of displacement of the solar spot on the surface of this second LEP is $1.1 \times 10^{-3} \mathrm{~mm}$ on both $\mathrm{X}$ and $\mathrm{Y}$ directions. This is associated with an experimental total angular error of $\theta=2.2 \times 10^{-5} \mathrm{rad}\left(\theta=1.3 \times 10^{-3 \circ}\right)$. This error is twice (Delahaigue et al. [9]) or three times (Gisi et al. [15]) better than in other systems where the distance $L$ is respectively three and four times smaller. So in input of this second lens, the maximum shift $(\delta)$ of the solar beam is $\delta=L \times \theta=10^{-4} \mu \mathrm{m}$. Figure 8 (c) and Figure 9 (c) also show the ability of the servo loop to stabilize the direction of the output beam and to compensate the effects of mechanical/thermal/alignment defects of the heliostat.

The servo control described here can only exist if the LEP is illuminated: it depends strongly on the weather conditions (clouds). Thus the control program provides for the switchover from the servo mode to a calculated mode (based on the ephemeris) when the intensity measured by the LEP is less than a threshold value. Similarly, switching from the calculated mode to the servo mode is performed automatically when the intensity is sufficient anew.

We have compared our servo loop efficiancy to Volkov et al.'s method [20]. They have chosen to determine theoretically the correction to apply on Euler angles to rectify the correspondence between the theoretical and real coordinate systems. They obtained an experimental stability of $0.01^{\circ}$. In our case, we have calibrated the instrument by projecting the axis of the rotation stages on that of the servo LEP to get an angular error 10 times smaller $\left(2.2 \times 10^{-5} \mathrm{rad}\right)$.

\section{Atmospheric spectra}

Down the skylight, solar beam reaches a $11 \mathrm{~cm}$ diameter. A 3" diameter part of the beam is taken and its size is reduced by a factor 4.5 by the use two off-axis parabolic mirrors. This beam shaping is suitable for direct injection, ultimately, in a heterodyne spectrometer currently developed at our laboratory from optical diameter of 1 ".

In order to test the heliostat performances for spectroscopy, the system is also adapted to inject the solar beam in a Fourier Transform Infrared spectrometer 
(FTIR, Jasco 6300) which is located at the other end of the room. There are $4 \mathrm{~m}$ between the skylight output and the FTIR spectrometer. So an additional optical system consisting of two spherical confocal mirrors $\left(f_{1}^{\prime}=100 \mathrm{~mm}\right.$ et $f_{2}^{\prime}=200 \mathrm{~mm}$ ) is added in order to adapt the beam to the spectrometer entry: the beam size is divided by a factor two. Thus unlike all other instruments presented in the literature (for which the spectrometer should be placed just next to their servo control captor), there are $\approx 14 \mathrm{~m}$ from our servo system up to our FTIR spectrometer. Our heliostat has enabled us to record atmospheric spectra during $10 \mathrm{~h}$ without interruption (no optical realignment, no anarchic response at the zenith), and with a $0.15 \mathrm{~cm}^{-1}$ resolution. One of those spectra is presented on the top of Figure 10, and compared with simulations in the $900 \mathrm{~cm}^{-1}-1200 \mathrm{~cm}^{-1}$ range.

The simulated spectra were obtained with the $4 \mathrm{~A} / \mathrm{OP}$ radiative transfer calculation software using several database notably the GEISA 2011 database $[28,29]$. It has been used to estimate the radiance at ground level. However, it may differ slightly from experimental spectrum because 4A/OP provides two default types of profiles (pressure, temperature, main molecules concentration), corresponding to tropical and polar environments. None of them are really suitable for mid-latitudes. We have chosen to use a polar atmosphere profile which is a priori closer to real conditions, especially for the amount of water vapor. There is a good agreement between the recorded spectrum and the simulation reported in the middle of Figure 10. But we can note that the calculated spectrum has deeper transitions than the recorded one. This is explained by the non-inclusion of the apparatus function of the spectrometer. Convoluting the calculated spectrum with a $0.15 \mathrm{~cm}^{-1}$-width-Gaussian function, the spectrum is in better agreement with the measure, as it is shown at the bottom of Figure 10.

We compare also the measured spectrum with the simulated absorption spectra of different atmospheric molecules (4A/OP software): ozone, water vapor, carbon dioxide and nitrous oxide in the $900 \mathrm{~cm}^{-1}-1200 \mathrm{~cm}^{-1}$ range (Figure 11). Their respective contributions to the total absorption can be identified. Indeed one can distinguish in particular the characteristic shape of the 
absorption band of $\mathrm{O}_{3}$ around $1050 \mathrm{~cm}^{-1}$, the contribution of water lines in $900 \mathrm{~cm}^{-1}-1000 \mathrm{~cm}^{-1}$ and $1100 \mathrm{~cm}^{-1}-1200 \mathrm{~cm}^{-1}$ ranges, the two absorption bands of $\mathrm{CO}_{2}$ between $900 \mathrm{~cm}^{-1}$ and $1100 \mathrm{~cm}^{-1}$, and the band of $\mathrm{N}_{2} \mathrm{O}$ between $1150 \mathrm{~cm}^{-1}$ and $1200 \mathrm{~cm}^{-1}$. The agreement between this experimental spectrum and the simulations confirms the relevance of the heliostat for spectrometry analysis.

\section{Conclusion}

The heliostat presented here operates without loss of control of the servo loop as it approaches the zenith. It enables to track the Sun for a whole day regardless of the time of year (measurements made made at differents times of the year). The servo-control method developed in this work is effective enough to collect a solar beam and to stabilize it with an total angular error of $2.2 \times 10^{-5} \mathrm{rad}$. According to our knowledge, this stability is better than the other suntrackers described in the literature. Unlike other published systems, thanks to this great stability, the instrument that we designed and implemented can be located at a great distance from the spectrometer (the beam propagates in a $14 \mathrm{~m}$-free space). The relevance of the instrument for spectroscopic measurements was validated by the record of atmospheric spectra by FTIR spectrometry which are in agreement with the simulation.

\section{Acknowledgements}

This work was funded by the ANR ASTRID Project \#ANR 12-ASTR0028 called QUIGARDE (2013-2016). The authors are also indebted to the

Délégation Générale de l'Armement and the Centre National de la Recherche Scientifique for financial support of the PhD of Marie-Hélène Mammez.

\section{References}

[1] G. Gagliardi and H.-P. Loock. Cavity-Enhanced Spectroscopy and Sensing. Springer Berlin Heidelberg, Berlin, Heidelberg, 2014. 
[2] K. H. Michaelian. Photoacoustic IR spectroscopy instrumentation, applications and data analysis. Wiley-VCH, Weinheim, 2010.

[3] C. Weitkamp, editor. Lidar : range-resolved optical remote sensing of the atmosphere, volume 102 of Springer Series in Optical Sciences. Springer, New York, 2005.

[4] B. Parvitte, V. Zéninari, C. Thiébeaux, A. Delahaigue, and D. Courtois. Infrared laser heterodyne systems. Spectrochimica Acta Part A, 60(5):1193$1213,2004$.

[5] B. Parvitte, L. Joly, V. Zéninari, and D. Courtois. Preliminary results of heterodyne detection with quantum-cascade lasers in the $9 \mu \mathrm{m}$ region. Spectrochimica Acta Part A, 60(14):3285-3290, 2004.

[6] D. Weidmann, W. J. Reburn, and K. M. Smith. Ground-based prototype quantum cascade laser heterodyne radiometer for atmospheric studies. Review of Scientific Instruments, 78(7):073107-10, 2007.

[7] G. Sonnabend, D. Wirtz, F. Schmlling, and R. T. Schieder. Tuneable heterodyne infrared spectrometer for atmospheric and astronomical studies. Applied Optics, 41(15):2978-84, 52002.

[8] R.P. Cageao, J.-F. Blavier, J.P. Mc Guire, Y. Jiang, V. Nemtchinov, F.P. Mills, and S.P. Sander. High-resolution fourier-transform ultravioletvisible spectrometer for the measurement of atmospheric trace species: Application to OH. Applied Optics, 40(12):2024-2030, 2001.

[9] A. Delahaigue, C. Thiébeaux, D. Courtois, and H. Le Corre. Design of a sun tracker for a laser heterodyne spectrometer. Infrared Physics, 28(1):1-6, 1988.

[10] M. C. Geibel, C. Gerbig, and Dietrich G. Feist. A new fully automated FTIR system for total column measurements of greenhouse gases. Atmospheric Measurement Techniques, 3(5):1363-1375, 102010. 
[11] Y. Té, P. Jeseck, S. Payan, I. Pépin, and C. Camy-Peyret. The Fourier transform spectrometer of the Université Pierre et Marie Curie QualAir platform. Review of Scientific Instruments, 81(10):103102, 102010.

[12] Bruker Optics. SOLAR TRACKER A 547 accessory manual, 1st revised edition edition, 2005.

[13] P.E. Ciddor. Refractive index of air: New equations for the visible and near infrared. Applied Optics, 35(9):1566-1573, 1996.

[14] A. Merlaud, M. De Mazire, C. Hermans, and A. Cornet. Equations for solar tracking. Sensors, 12(4):4074-90, 2012.

[15] M. Gisi, F. Hase, S. Dohe, and T. Blumenstock. Camtracker: a new camera controlled high precision solar tracker system for ftir-spectrometers. Atmospheric Measurement Techniques, 4(1):47-54, 12011.

[16] X. Jin, G. Xu, R. Zhou, X. Luo, and Y. Quan. A sun tracking system design for a large dish solar concentrator. International Journal of Clean Coal and Energy, 2:16-20, 2013.

[17] K.-K. Chong and C.-W. Wong. General formula for on-axis sun-tracking system and its application in improving tracking accuracy of solar collector. Solar Energy, 83(3):298-305, 2009.

[18] K.-K. Chong, C.-W. Wong, F.-L. Siaw, T.-K. Yew, S.-S. Ng, M.-S. Liang, Y.-S. Lim, and S.-L. Lau. Integration of an on-axis general sun-tracking formula in the algorithm of an open-loop sun-tracking system. Sensors, 9(10):7849-65, 2009.

[19] K.-K. Chong and C.-W. Wong. General Formula for On-Axis Sun-Tracking System, chapter 13, pages 263-292. Manyala, Reccab, 2010.

[20] S. N. Volkov, I. V. Samokhvalov, H. D. Cheong, and D. Kim. Optical model and calibration of a sun tracker. Journal of Quantitative Spectroscopy and Radiative Transfer, 180:101 - 108, 2016. 
[21] J. E. Franklin. Solar Absorption Spectroscopy at the Dalhousie Atmospheric Observatory. PhD thesis, Dalhousie University, 2015.

[22] J. Chen, C. Viatte, J. K. Hedelius, T. Jones, J. E. Franklin, H. Parker, E. W. Gottlieb, P. O. Wennberg, M. K. Dubey, and S. C. Wofsy. Differential column measurements using compact solar-tracking spectrometers. Atmospheric Chemistry and Physics, 16(13):8479-8498, 2016.

[23] J. Meeus. Astronomical algorithms. Atlantic books, 1998.

[24] I. Reda and A. Andreas. Solar position algorithm for solar radiation applications. Technical Report NREL/TP-560-34302, National Renewable Energy Laboratory, 12008.

[25] M.-H. Mammez. Détection hétérodyne de molécules d'intérêt atmosphérique à l'aide de lasers à cascade quantique. PhD thesis, Université de Reims Champagne-Ardenne, 2016.

[26] C.-Y. Lee, P.-C. Chou, C.-M. Chiang, and C.-F. Lin. Sun tracking systems: a review. Sensors (Basel), 9(5):3875-90, 2009.

[27] P. Roth, A. Georgiev, and H. Boudinov. Design and construction of a system for sun-tracking. Renewable Energy, 29(3):393-402, 2004.

[28] N. A. Scott and A. Chédin. A fast line-by-line method for atmospheric absorption computations: The automatized atmospheric absorption atlas. Journal of Applied Meteorology, 20(7):802-812, 1981.

[29] L. Chaumat, C. Standfuss, B. Tournier, E. Bernard, Raymond Armante, and N. A. Scott. 4A/OP Reference documentation. NOV-3049-NT-1178v4.3. NOVELTIS, LMD/CNRS, CNES, 2012. 

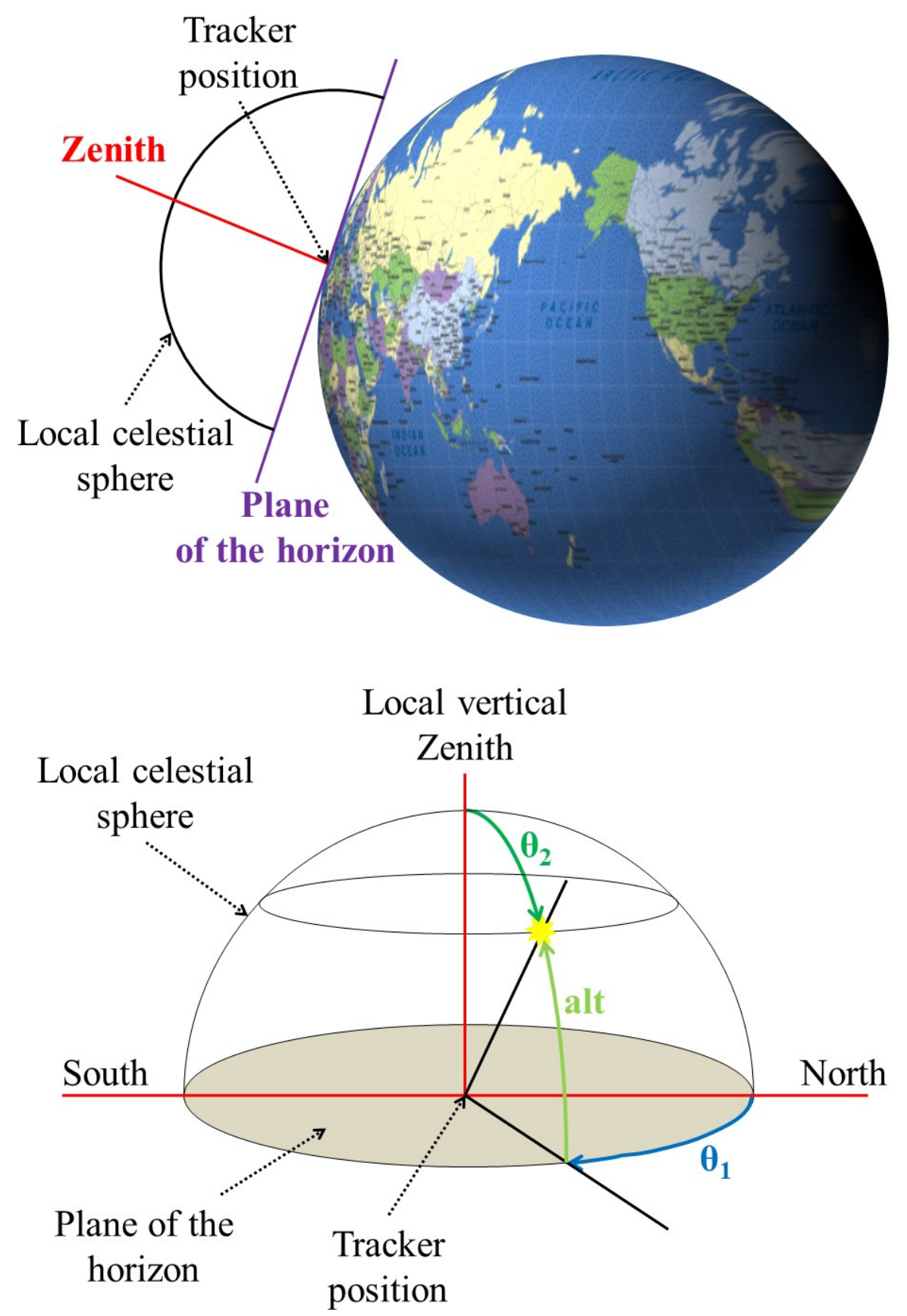

Figure 3: (Top) The topocentric coordinate system is built with the location of the heliostat as the origin point of the reference, the local vertical and the tangent plane to the Earth. (Bottom) The zenithal angle $\theta_{2}$ is measured from the local vertical. The azimuth $\theta_{1}$ is measured in the perpendicular plane from the North to the East. 

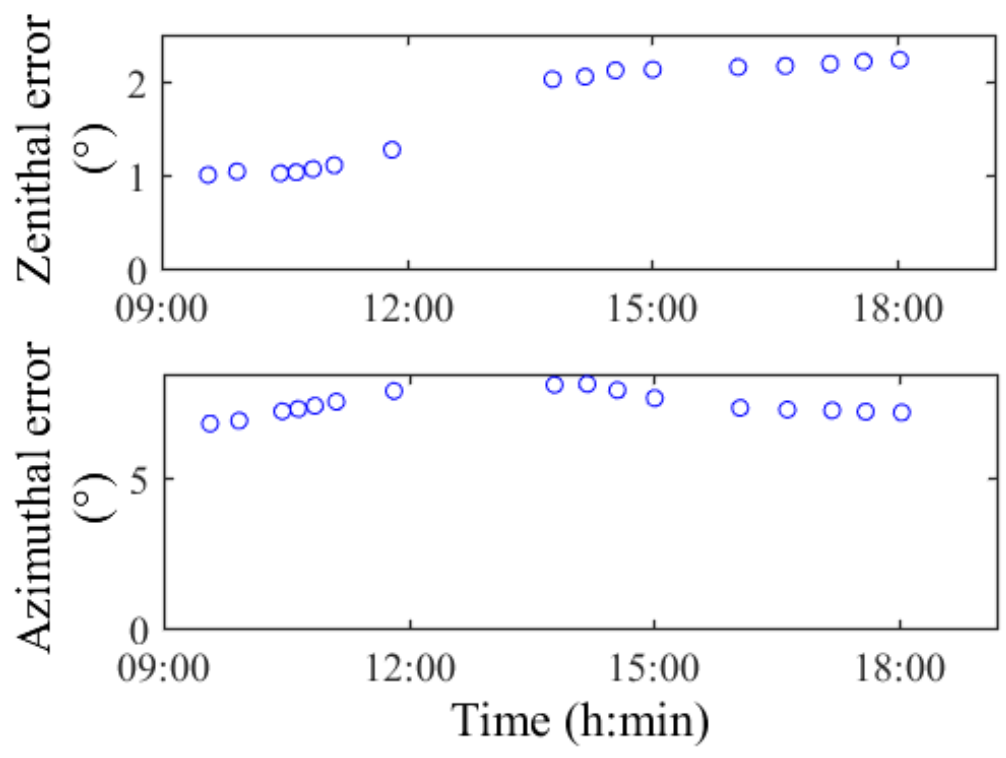

(a)

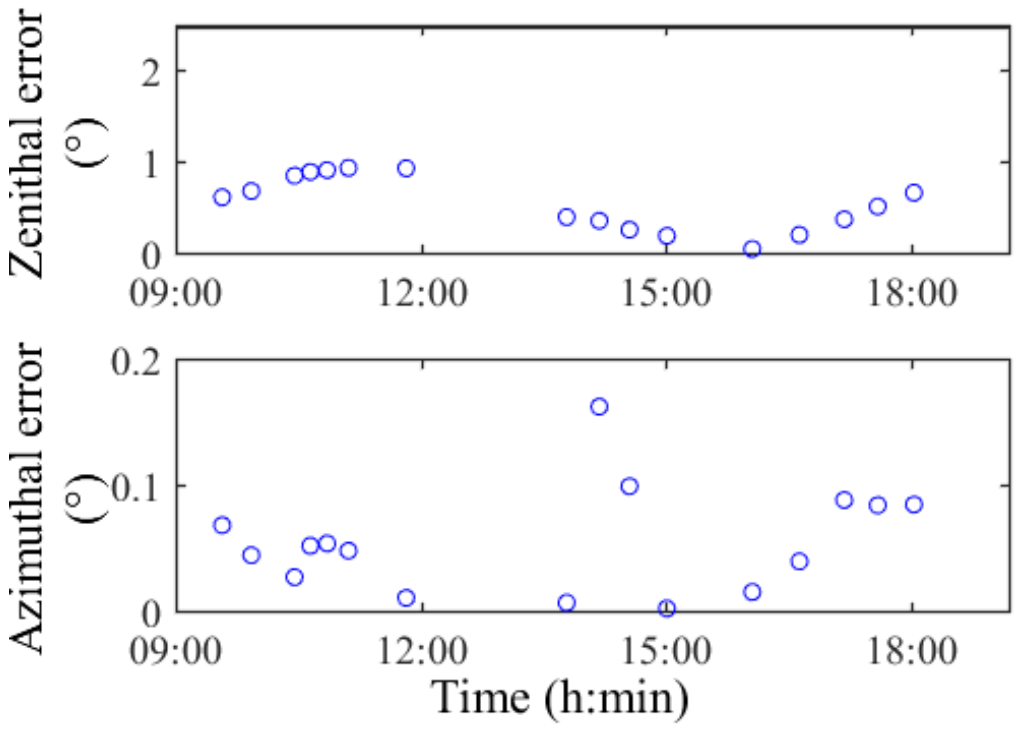

(b)

Figure 4: Calculated mode operation (without servo control). (a) Error measured before correction. (b) Error measured after correction. The correction of the calculation by the calibration improves the error |measured-calculated| of the stages positions by $59 \%$ for zenithal angles and by $99 \%$ for azimuths. 


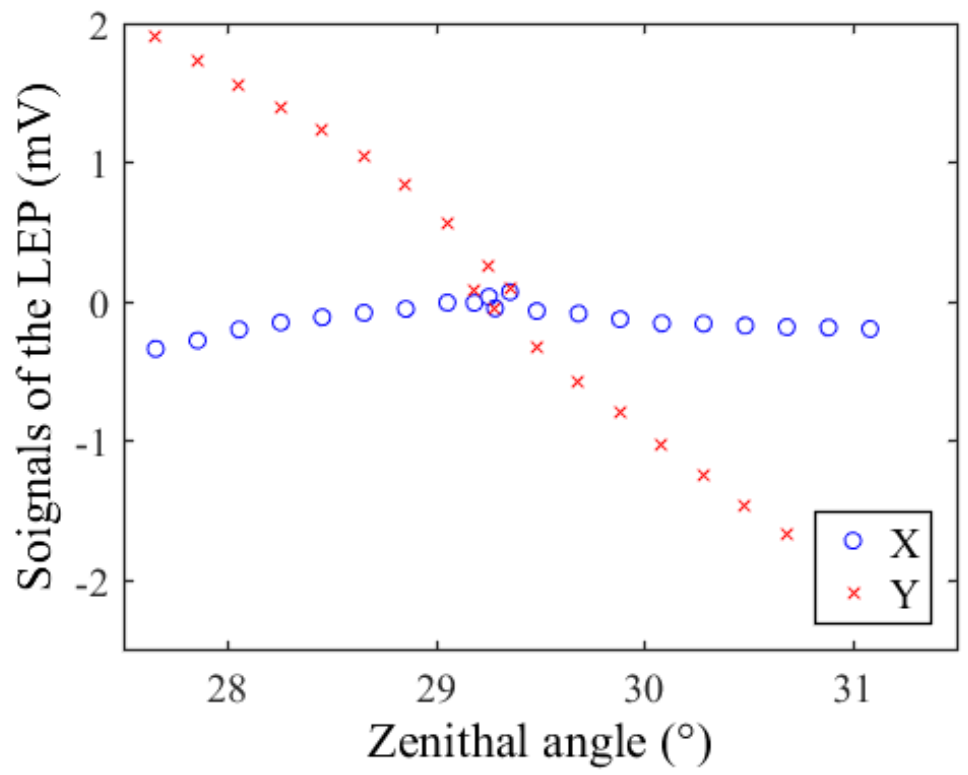

(a)

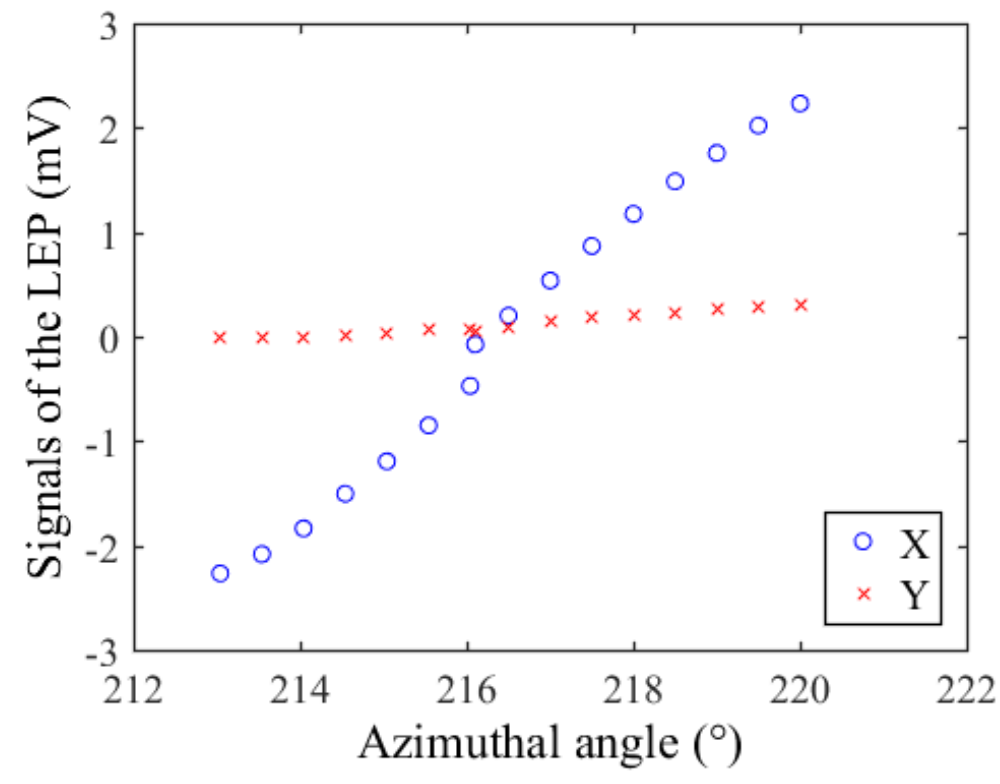

(b)

Figure 5: Evolution of the position (X, Y) of the beam on the LEP highlighting the coupling of error signals. The servo control is turned off and the stages are manually turned to show the movement induced on the beam by each of them. $\mathrm{X}$ and $\mathrm{Y}$ are the coodinates of the spot on the LEP and correspond to the error signals. (a) Movement induced on the solar beam by the zenithal stage. (b) Movement induced on the solar beam by the azimuthal stage. 

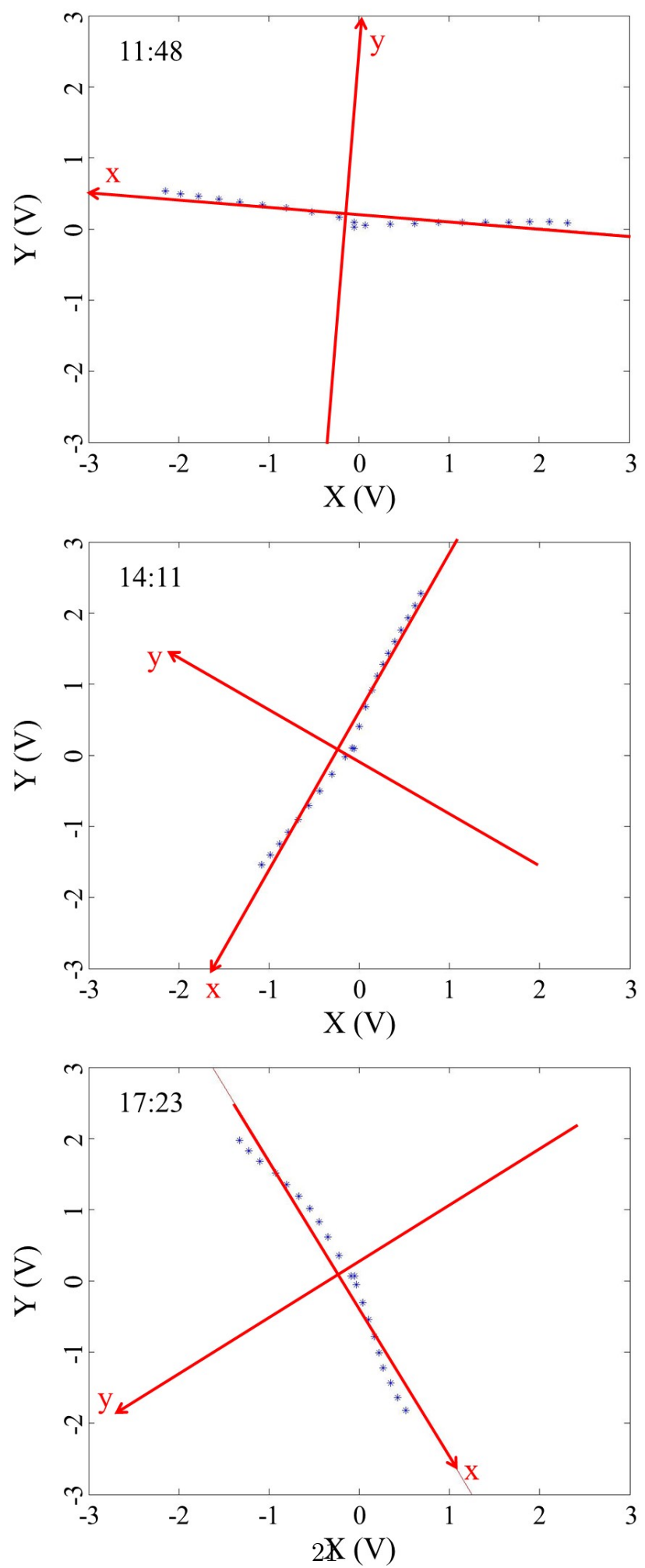

Figure 6: Rotation during the day of the altazimuthal system in the coordinate system of the LEP. The servo control is temporally turned off and azimuthal stage is manually rotated to highlight the rotation of the projection in the LEP reference of the azimuthal axis. As the zenithal axis is always perpendicular to azimuthal one, we can deduce the rotation of the projection of the zenithal axis. $\mathrm{X}$ and $\mathrm{Y}$ correspond to the axis of the LEP. $\mathrm{x}$ and $\mathrm{y}$ are the axis of the altazimuthal system. $\mathrm{x}$ (respectively $\mathrm{y}$ ) depends on $\mathrm{X}$ and $\mathrm{Y}$. So it involves a coupled error signals generation. 


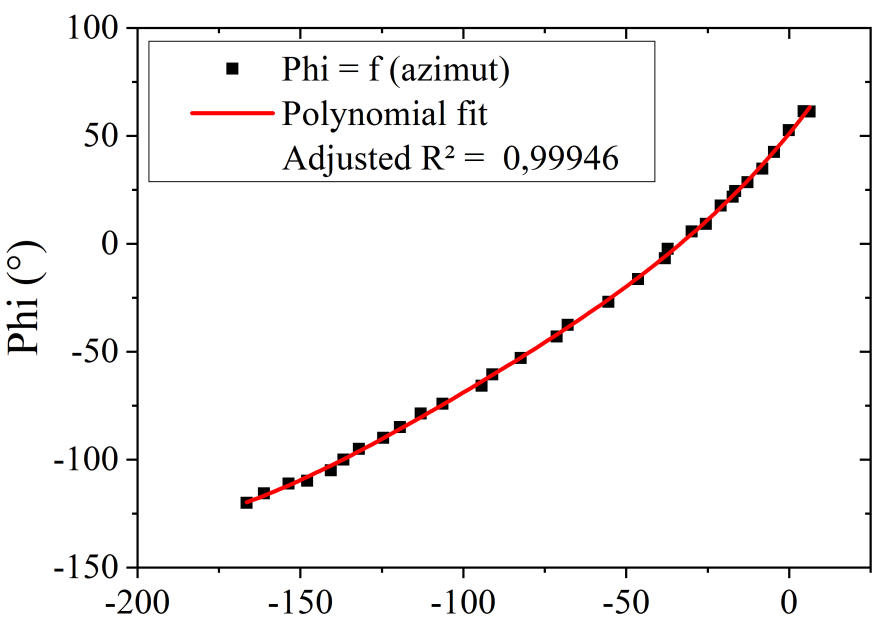

Angle on azimuthal rotation stage $\left(^{\circ}\right)$

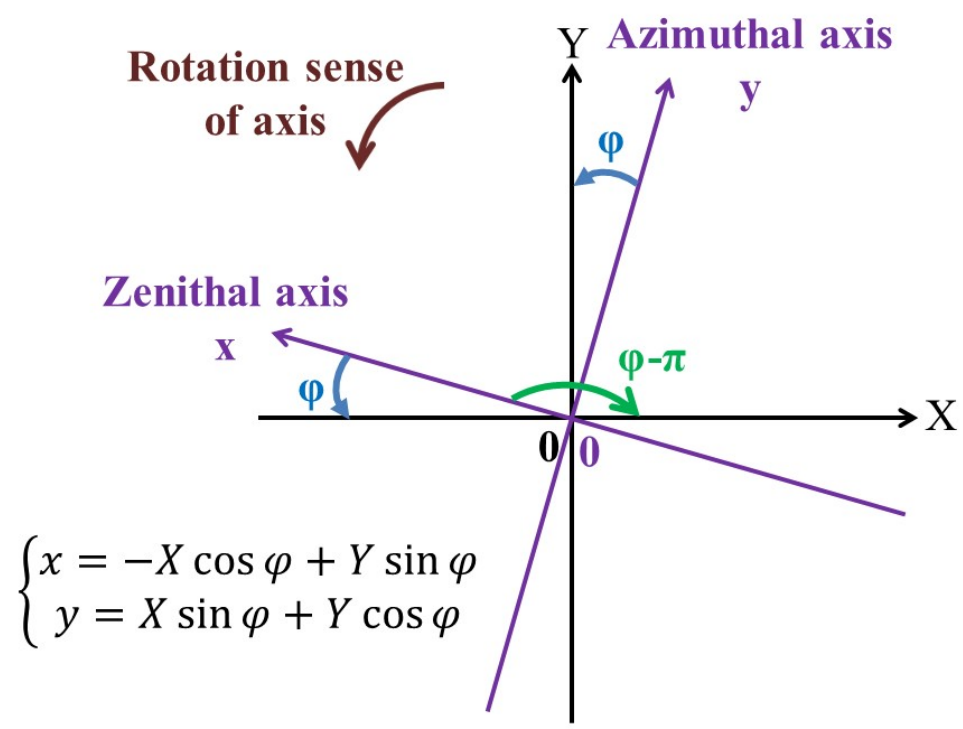

(b)

Figure 7: Determination of uncoupled error signals for azimuthal and zenithal stages servo control. (a) Calibration of $\varphi$ depending of the azimuthal angle value. (b) Principle of conversion of $(\mathrm{X}, \mathrm{Y})$ coordinates into $(\mathrm{x}, \mathrm{y})$ coordinates. $\mathrm{X}$ and $\mathrm{Y}$ correspond to coupled error signals, whereas $\mathrm{x}$ and $\mathrm{y}$ are uncoupled error signals. 


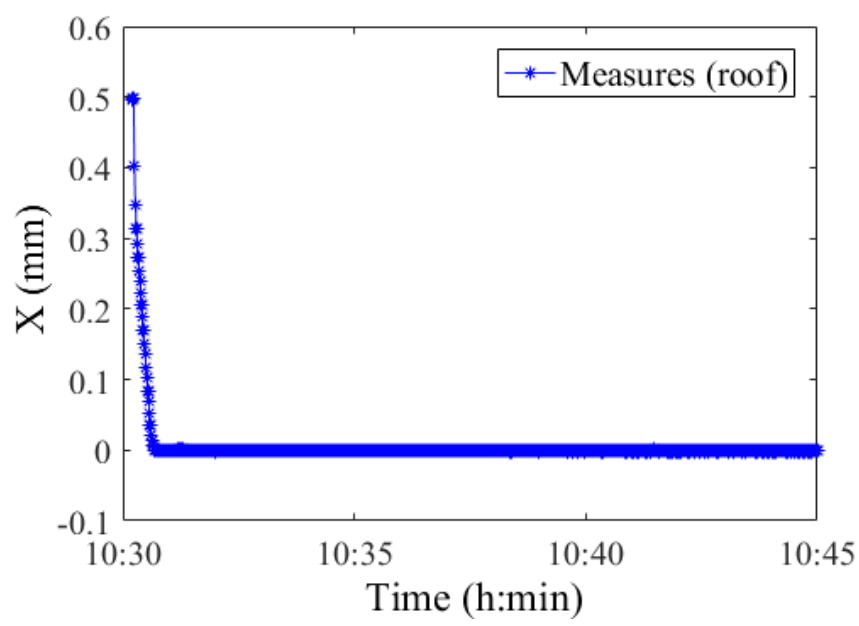

(a)
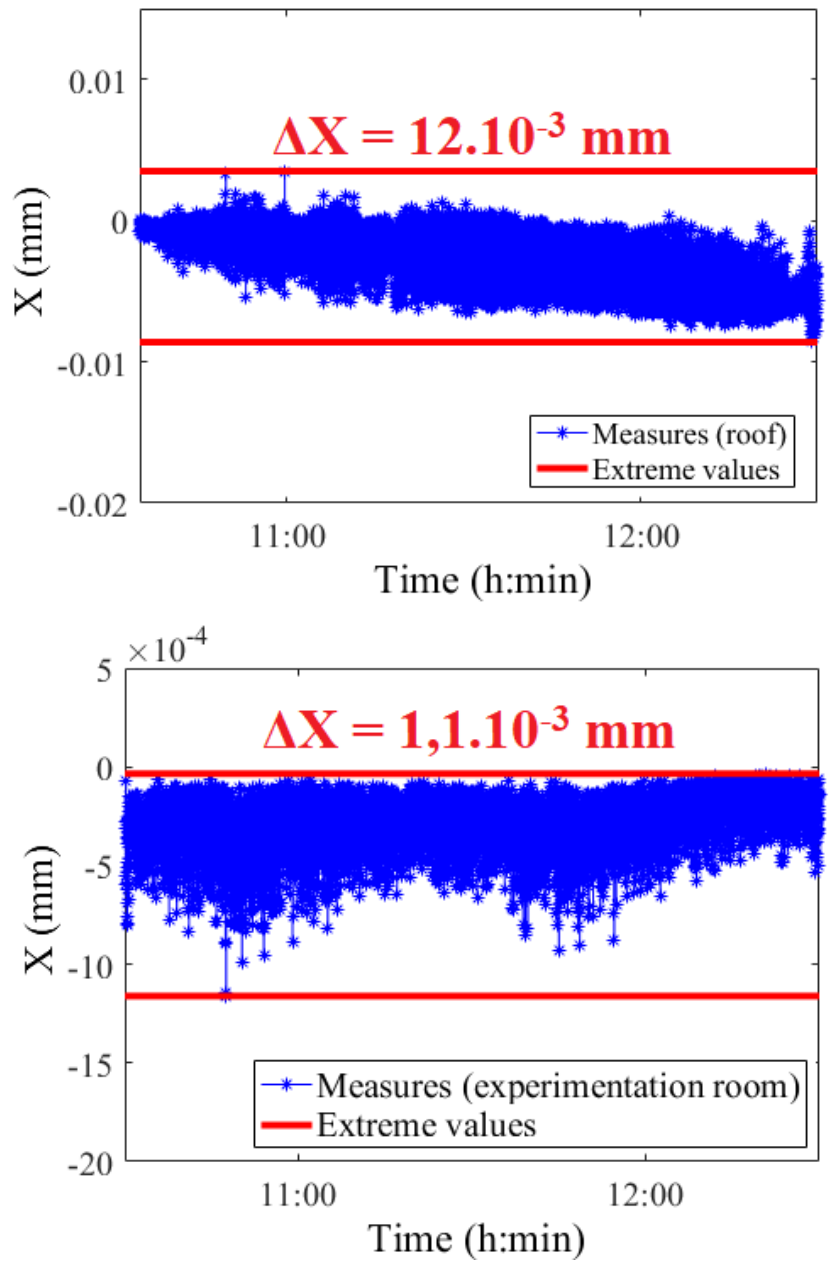

(b)

(c)

Figure 8: (a) Servo-controlled suntracking beised on the coordinate system rotation of the heliostat. $\mathrm{X}$ is the first cartesian coordinate respect to the center of the LEP. Its behavior is similar to a conventional PID-based servo control. (b) Stability of the solar spot at the top of the skylight $\left(L_{0} \approx 1 \mathrm{~m}\right)$ and after focusing using a $\mathrm{BaF}_{2}$ lens of $12.5 \mathrm{~cm}$-focal length. (c) Beam stability down the skylight $(L \approx 10 \mathrm{~m})$ and after focusing using another $\mathrm{BaF}_{2}$ lens of $50 \mathrm{~mm}$-focal length. Resolution of the LEP : $0.8 \mu \mathrm{m}$. 


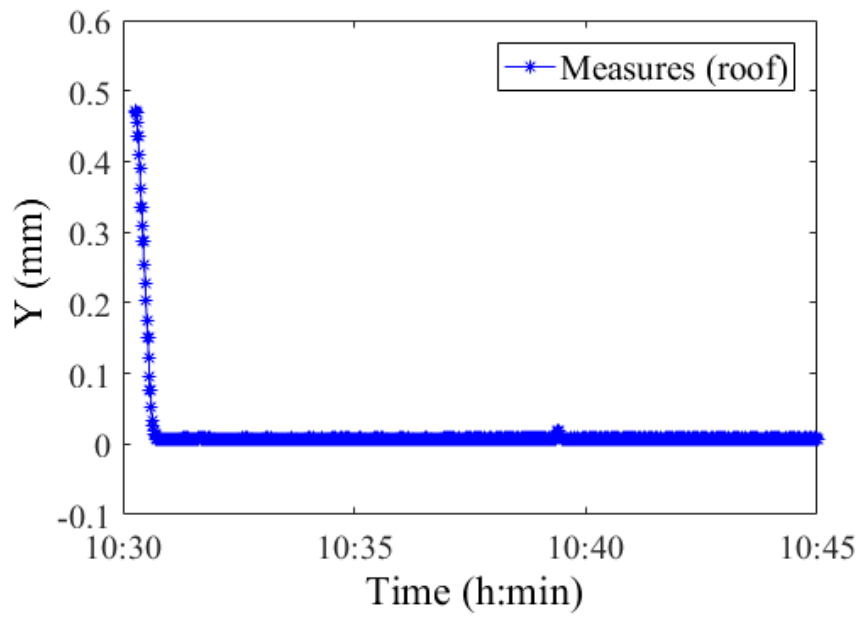

(a)
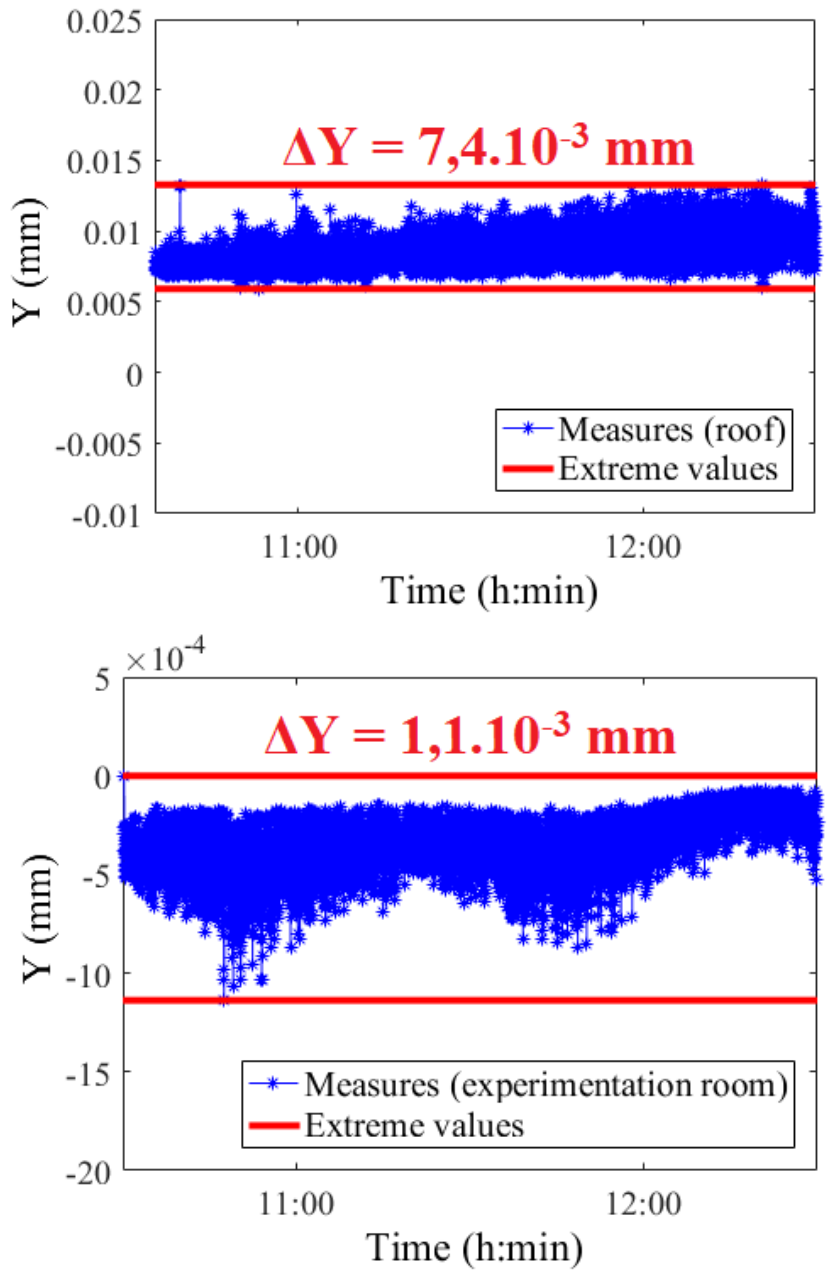

(b)

(c)

Figure 9: (a) Servo-controlled suntracking betsed on the coordinate system rotation of the heliostat. $\mathrm{Y}$ is the second cartesian coordinate respect to the center of the LEP. As for the $\mathrm{X}$ coodinate, its behavior is similar to a conventional PID-based servo control. (b) Stability of the solar spot at the top of the skylight $\left(L_{0} \approx 1 \mathrm{~m}\right)$ and after focusing using a $\mathrm{BaF}_{2}$ lens of $12.5 \mathrm{~cm}$-focal length. (c) Beam stability down the skylight $(L \approx 10 \mathrm{~m})$ and after focusing using another $\mathrm{BaF}_{2}$ lens of $50 \mathrm{~mm}$-focal length. Resolution of the LEP : $0.8 \mu \mathrm{m}$. 

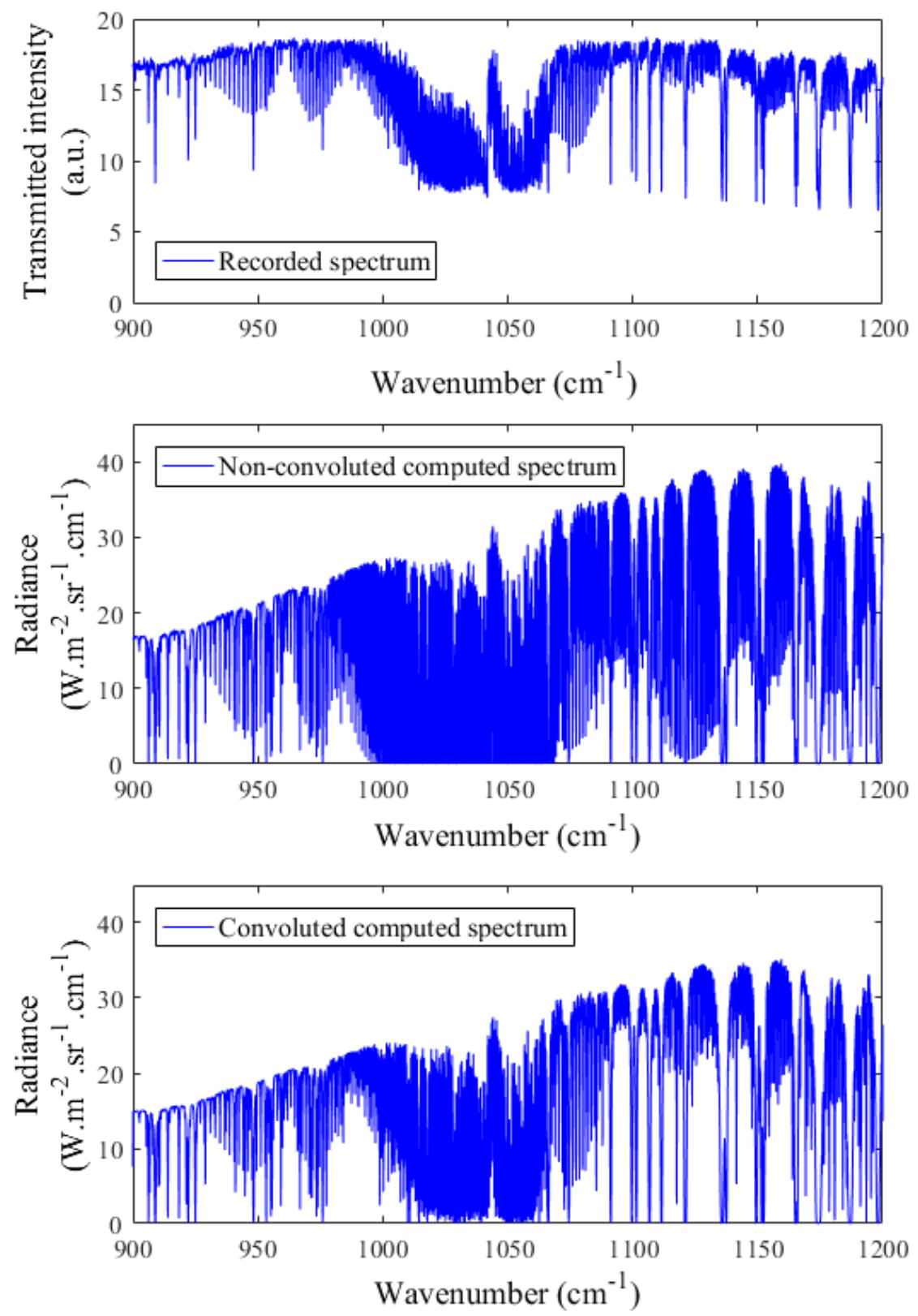

Figure 10: (Top) Experimental spectrum recorded at $14 \mathrm{~m}$ from the heliostat by a FTIR spectrometer (accumulation of 40 spectra for $10 \mathrm{~min}$ on a $\mathrm{HgCdTe}$ detector and with a resolution of $0.15 \mathrm{~cm}^{-1}$ ). (Middle) Non-convoluted simulated spectrum. (Bottom) Simulated spectrum convoluted by a $0.15 \mathrm{~cm}^{-1}$-width Gaussian function. The simulations were performed with the $4 \mathrm{~A} / \mathrm{OP}$ software. 

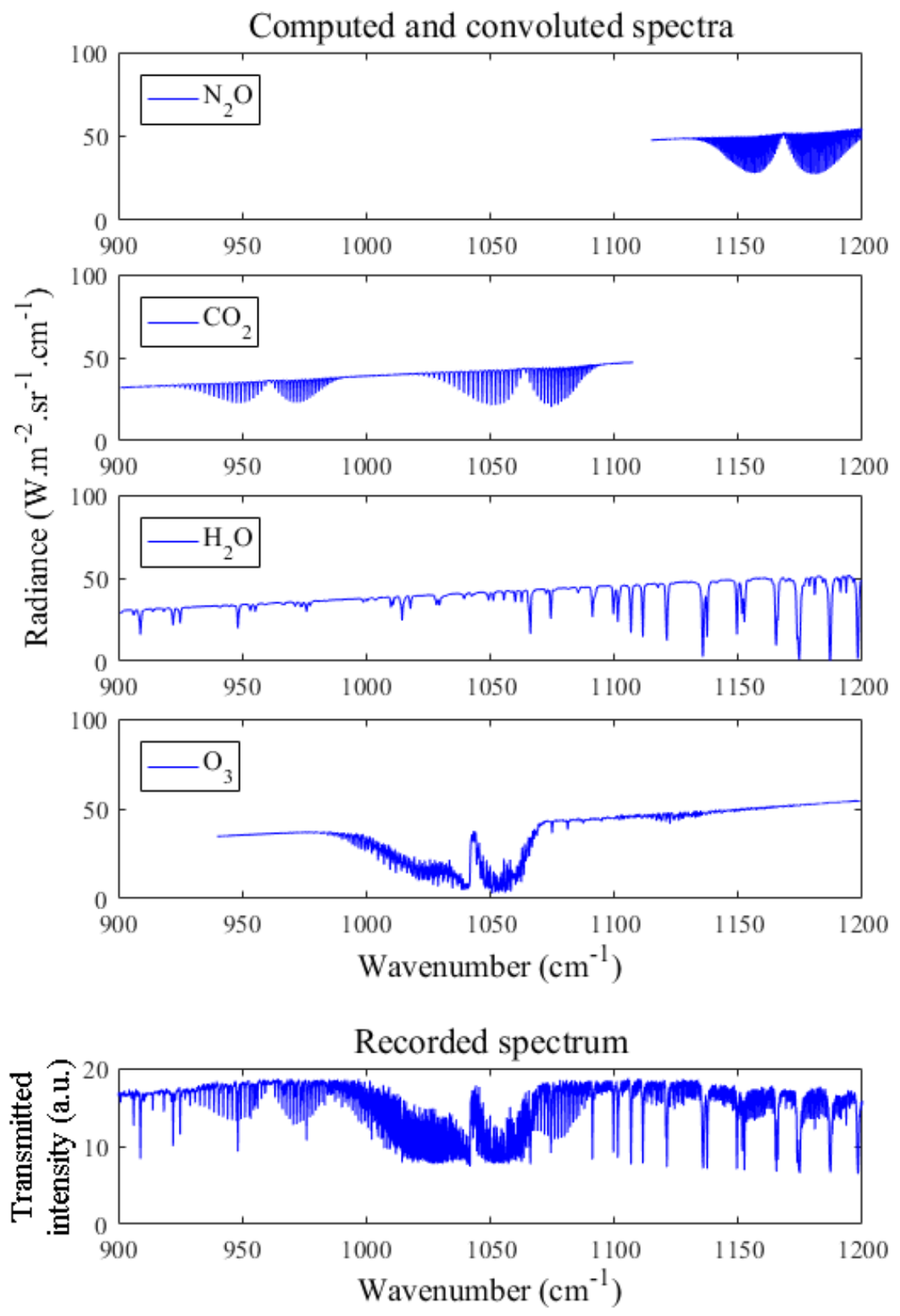

Figure 11: Contribution of some atmospheric gases $\left(\mathrm{N}_{2} \mathrm{O}, \mathrm{CO}_{2}, \mathrm{H}_{2} \mathrm{O}\right.$ and $\left.\mathrm{O}_{3}\right)$ to the experimental absorption spectrum (FTIR measurement by the accumulation of 40 spectra for 10 min on a $\mathrm{HgCdTe}$ detector and with a resolution of $0.15 \mathrm{~cm}^{-1}$ ). As on Figure 10, the simulations are computed with the $4 \mathrm{~A} / \mathrm{OP}$ software. 